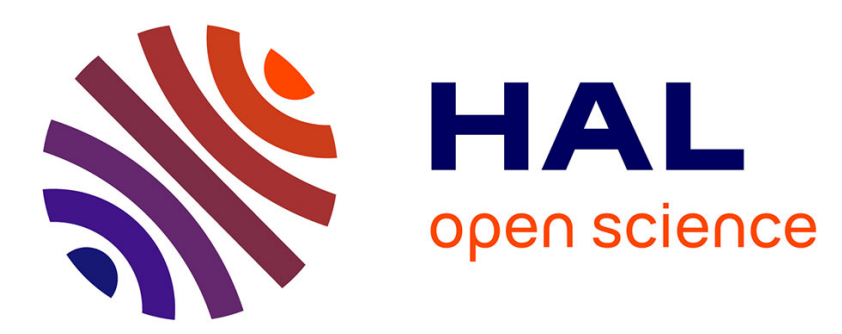

\title{
Direct usage of the wire drawing process for large strain parameter identification
}

Gabriel Venet, Tudor Balan, Cyrille Baudouin, Régis Bigot

\section{To cite this version:}

Gabriel Venet, Tudor Balan, Cyrille Baudouin, Régis Bigot. Direct usage of the wire drawing process for large strain parameter identification. International Journal of Material Forming, 2018, 12 (5), pp.875-888. 10.1007/s12289-018-01458-z . hal-02297708

\section{HAL Id: hal-02297708 \\ https://hal.science/hal-02297708}

Submitted on 26 Sep 2019

HAL is a multi-disciplinary open access archive for the deposit and dissemination of scientific research documents, whether they are published or not. The documents may come from teaching and research institutions in France or abroad, or from public or private research centers.
L'archive ouverte pluridisciplinaire HAL, est destinée au dépôt et à la diffusion de documents scientifiques de niveau recherche, publiés ou non, émanant des établissements d'enseignement et de recherche français ou étrangers, des laboratoires publics ou privés. 


\title{
Direct usage of the wire drawing process for large strain parameter identification
}

\author{
Gabriel Venet, Tudor Balan*, Cyrille Baudouin, Régis Bigot \\ Université de Lorraine, Arts et Métiers ParisTech, LCFC, F-57000 Metz, France
}

\begin{abstract}
Large strain hardening is the main material description ingredient for cold bulk forming process simulations. Hardening identification of large strains is a trade-off between cost, standardization and the ability to represent the experiment, but there are no standard procedures to date. In this proposed approach, large strains (larger than 1) are reached using an industrial wire drawing process, and measured data for identification are obtained from standard tensile tests. Fast semi-analytical post-processing was possible despite the significant process-inherited strain heterogeneity. The parameters of state-of-the-art hardening models were identified, and the robustness was demonstrated to reach far beyond the strain level attained in the experiments. As a consequence, accurate and robust large strain hardening modelling was achieved from standard (tensile test) acquisition by using industrial wire drawing pre-strains.
\end{abstract}

Keywords: Forging; hardening; identification; large strain

\footnotetext{
* Corresponding author. Tel: +(33)3.87.37.54.60. E-mail: tudor.balan@ensam.eu
} 


\section{Introduction}

Metal forming process simulations using the finite element method (FEM) has become a common engineering tool for use in industry. The material model is one of the key ingredients dictating the predictive ability of such software. In parallel with the development of advanced material models, there is a necessity to identify the parameters associated with these models for different materials.

Material models attempt to describe the effects of the different physical mechanisms that occur during and after the deformation of the metal like dislocation generation and pile-up, grain refinement, recrystallization, recovery, texture evolution, etc. These deformation mechanisms are induced at macroscopic scale by strain, temperature and strain rate, which have an influence over the hardening or softening of the metal. Physically-based models have been proposed to take into account these phenomena, based on the early works of Avrami [1]. Alternatively, phenomenological models have been proposed at the macroscopic scale, in order to heuristically describe the experimentally observed macroscopic behaviour. Critical reviews of both model families are available in the literature (see, e.g., [2]), showing that both are suitable to describe complex mechanical behaviour, with the first family predicting also certain evolutions at microstructure scale. It is noteworthy that FEM simulation software are mainly based on phenomenological models, because of their reduced number of material constants that can be identified more easily [3].

Modern parameter identification methods were established approximately two decades ago to support the massive dissemination of FE simulations in the metal forming industry. FE-based inverse methods allowed accurate consideration of the actual geometry, strain rate and temperature conditions in a test sample, along with any heterogeneity [4], [5]. Various testing methods were proposed to reach the desired strain range and strain rates. In particular, compression (uniaxial or plane strain) and torsion tests have been able to reach large strain levels compatible with forging applications [2], [6]. As a consequence, at the end of the last century, complete databases with material models and parameters were generated for most commercially available materials used for bulk metal forming. The robustness and affordability of these databases made them the first choice for industrial forming simulation.

With the recent evolution in metal forming, new issues have risen related to material parameter determination. Initially, the loading mode for typical characterization experiments is not necessarily the same as that during forging applications, raising questions about the applicability of the corresponding parameters. Thus, the development of adequate large strain characterization experiments is still a major topic of investigation for both bulk [2] and sheet [7] metal forming. More pragmatically, specific experimental equipment is required for such characterization, which is increasingly less compatible with current cost and time pressures on the forming industry. Indeed, characterization and identification skills are not easily found in the manufacturing industry, representing an external expense. However, new material grades are still being made available at a constant rate as a consequence of weight reduction strategies. Due to these contradictory trends, it is increasingly more common that parameters 
for new material grades are determined based on tensile tests, which is the experimental data supplied by material suppliers with each material batch.

Presently, material data of poor quality are being commonly used in numerical simulations despite the powerful methodologies available in the literature [8], [9]. In this paper, a pragmatic but rigorous parameter identification approach is proposed for bulk metal forming applications at room temperature, making use of tensile tests subsequent to industrial wire drawing sequences. Such sequential drawing experiments are already performed by steelmakers to determine the so-called ultimate drawing limit of a material [10], but they can also be used to characterize all the drawing processes [11]. As a consequence, the proposed procedure does not actually require additional tests but makes use of an existing experiment that permits the large strains required for proper characterization of hardening behaviour. Moreover, no data acquisition is required during these large strain experiments, meaning that only simple tensile tests are used for this purpose. Consequently, the experimental part for large strain parameter identification is significantly simplified, and the cost is reduced to a minimum. The accuracy and robustness of the results do not suffer from this simplification and are instead strengthened. The paper is limited to the family of phenomenological models, due to their extended usage in forming applications.

The outline of this paper is as follows. The proposed experimental procedure is presented in Section 2, followed by the parameter identification methodology in Section 3. The results and their consequences are discussed in Section 4, before drawing the main conclusions.

\section{Experimental method and computation results}

The investigated material was a low-carbon steel wire of $7.5 \mathrm{~mm}$ diameter, which is typical for cold bulk forming, with a longitudinal initial yield stress of $Y S=400 \mathrm{MPa}$, an ultimate tensile strength of UTS $=635 \mathrm{MPa}$, and a tensile fracture strain of $A=31,9 \%$. The experiments consisted in a sequence of six wire drawing operations followed by as many tensile tests, plus one tensile test on the original material before the first wire drawing. A wire drawing forming process is schematically illustrated in Figure 1. The wire is drawn through a die to reduce its diameter. After each diameter reduction, tensile test samples are cut from the resulting wire. The remaining wire is drawn through another die to reduce again the diameter etc. 


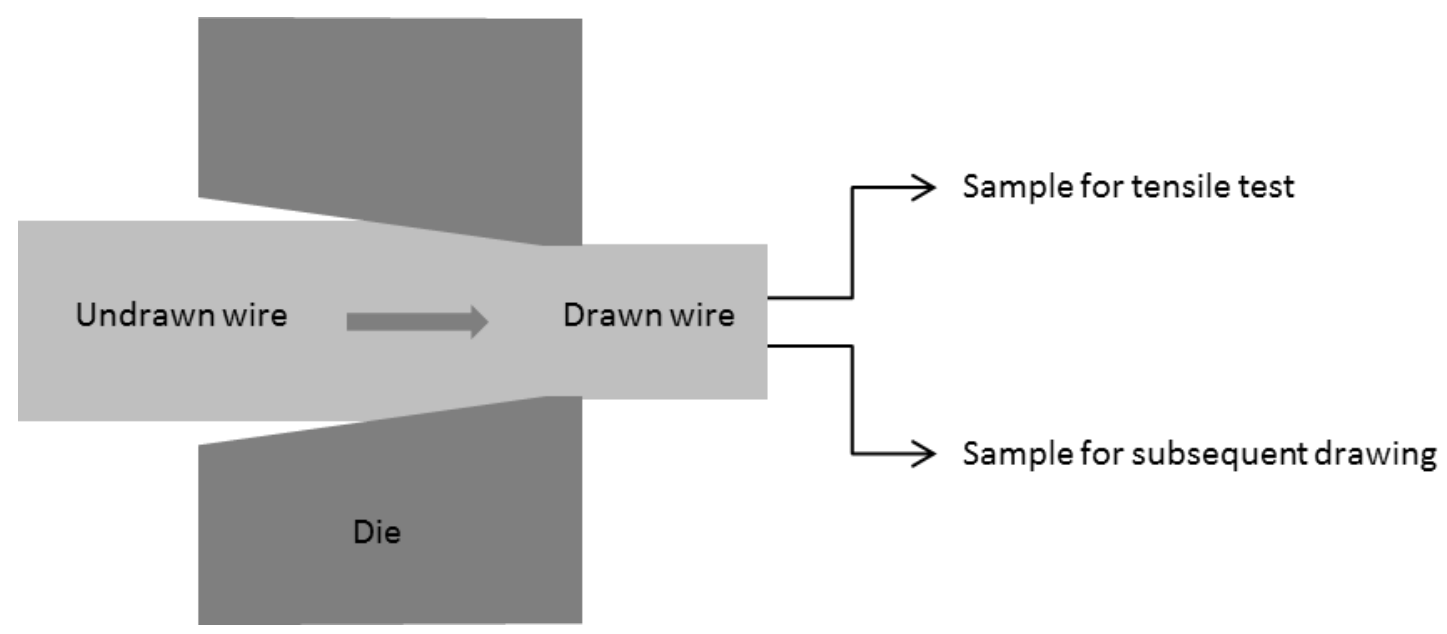

Figure 1. Schematic representation of a typical wire drawing operation within the multi-step wire drawing process used in the investigation, in preparation of the tensile tests series.

The drawing operations were used to reach large strain levels, as shown in Table 1 . The tensile tests served to record the material response at the various strain levels. The engineering strain is calculated as $\Delta L / L_{0}$, where $\Delta L$ is the change in length and $L_{0}$ the initial reference length of the sample. In practice, the length evolutions are determined from the diameter reduction using volume conservation. This use of the wire drawing to reach large strains is made here with the same approach as [11], under the assumption that equivalent plastic strain can be used as the single relevant hardening variable. This is of course a simplification of the physical reality. Young et al. [12], for example, have shown that the evolution of the flow stress vs equivalent plastic strain during wire drawing deviates from that revealed by torsion test. A fibrous texture of elongated subgrains is formed by drawing leading to a constant hardening slope, while more equiaxed subgrains are observed in torsion leading to a steady state flow stress. However, these differences appear only for true strain values larger than 2 . For lower strain values, multiple wire drawing and wire torsion were shown to reveal the same hardening curve. It is noteworthy that both these tests induce strain heterogeneity through the wire's cross-section. Consequently, a model needs to be elaborated to extract the yield stress from the measured force / torque evolution. In the case of multiple wire drawing, one cannot use single-pass analytical models [13] to predict the effects of a multi-pass configuration. Thus, in this article, each drawing pass will be simulated individually. The analysis of the multi-step wire drawing process itself is not the aim of the paper; in-depth studies can be found in the literature [14]-[16]. 
Table 1. Sequence of wire drawing operations and the resulting diameters and strains (initial diameter of the steel wire equal to $7.5 \mathrm{~mm}$ ).

\begin{tabular}{l|cccccc}
\hline Drawing pass number & 1 & 2 & 3 & 4 & 5 & 6 \\
\hline Wire diameter [mm] & 7.23 & 6.26 & 5.60 & 5.00 & 4.48 & 4.01 \\
Total engineering strain [\%] & 7.5 & 43 & 79 & 124 & 180 & 250 \\
\hline
\end{tabular}

Figure 2 shows the engineering stress vs. engineering strain curves for the seven wires. All the tensile curves were performed in triplicate to check repeatability. This sequential combination of a forming process and a standard characterization test allows for classical post-processing of the measured data, while large strains are reached by using an available industrial process.

In industrial wire drawing, the multiple drawing steps follow each other at great speed. Therefore, the metal is self-heating due to the large deformation in a short amount of time and thermal effects occur. However, in the case of this study, the process is interrupted after each drawing operation in order to cut the tensile test samples, and the material is cooled down at room temperature. This allows us to study the material at low temperature at any drawing sequence. On the other hand, the drawing sequence may induce significant heterogeneity in the strain field [14]. FE simulations were used to elucidate and quantify this effect.
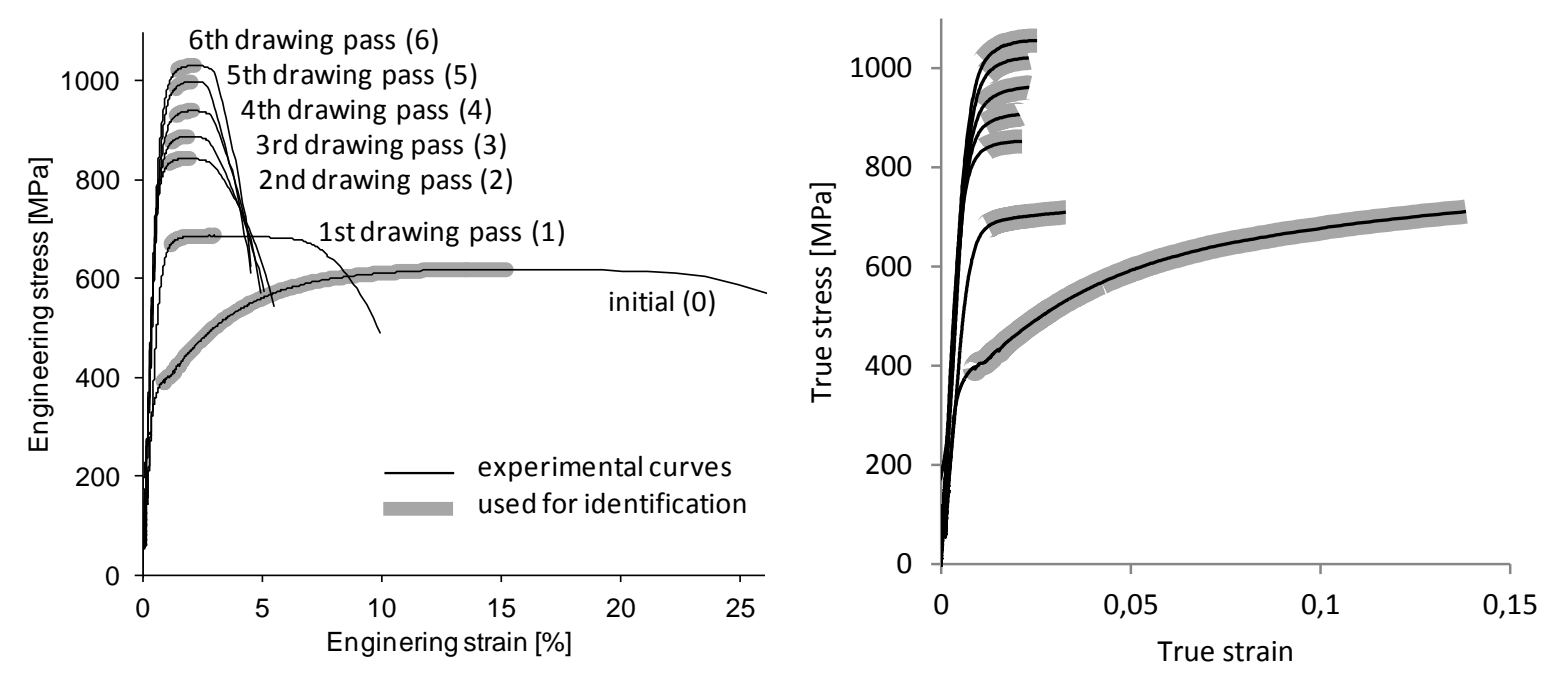

Figure 2. Experimental tensile engineering (left) and true (right) stress-strain curves for the initial and subsequently drawn wires. The thick grey lines show the fraction of the curves used for parameter identification. The curves are labelled with numbers that will be reused in the next figures. 
The wire drawing operations were simulated with the FE software Forge ${ }^{\circledR}$ Nxt 1.1. The material behaviour was described by a Hollomon law $\sigma=600 \varepsilon^{0.16}$, based on a previous study on the same wires [17]. Since temperature and rate sensitivity have a limited impact on the strain distribution during wire drawing, the corresponding parameters were selected from the database of Forge ${ }^{\circledR}$ Nxt. Similarly, friction was neglected in the simulations, thus the resulting strain heterogeneity can be considered as a lower bound of the experimental one. Axisymmetric 2D simulations were performed due to the symmetry of the wires, tools and loading. The mesh density was uniform and element size was selected so that about ten elements were present across the smallest wire radius, for the coarsest investigated mesh. The robustness of the results with respect to the selection of both material parameters and mesh density was numerically investigated, as shown hereafter.

The strain field in the wire cross-section was heterogeneous, following the same typical profile shown in Figures $3 \mathrm{a}$ and $3 \mathrm{~b}$. For each drawing sequence, the minimum strain was in the core of the wire. The strain value was well approximated by the analytical strain based on the cross-sectional area reduction but was slightly larger. The maximum strain for each drawn wire was reached a short distance from the outer skin. The relative strain variation across the wire's cross-section was as large as $129 \%$ after the first drawing, indicating that using the ideal drawing strains for parameter identification [17], [18] could lead to significant errors. Table 2 quantitatively illustrates the strain heterogeneity created by the process. It is clear that taking this heterogeneity into account is recommended to compute a proper simulation of the tensile test.

Table 2. Strain heterogeneity in the wires' cross-section, based on the equivalent strain values after each drawing pass at the middle of the wire $\left(\varepsilon_{0}\right)$, the point of maximal strain $\left(\varepsilon_{\max }\right)$ and the outer surface of the wire $\left(\varepsilon_{R}\right)$.

\begin{tabular}{|c|c|c|c|c|}
\hline $\begin{array}{c}\text { Drawing } \\
\text { pass \# }\end{array}$ & $\varepsilon_{0}$ & $\varepsilon_{\max }$ & $\varepsilon_{R}$ & $\frac{\varepsilon_{\max }-\varepsilon_{0}}{\varepsilon_{0}}(\%)$ \\
\hline 1 & 0.076 & 0.17 & 0.14 & 129 \\
\hline 2 & 0.35 & 0.51 & 0.41 & 46 \\
\hline 3 & 0.59 & 0.78 & 0.77 & 33 \\
\hline 4 & 0.81 & 1.09 & 1.03 & 35 \\
\hline 5 & 1.04 & 1.34 & 1.19 & 28 \\
\hline 6 & 1.29 & 1.59 & 1.42 & 23 \\
\hline
\end{tabular}

Numerical tests showed that the strain distribution was relatively robust with respect to any changes in the numerical parameters (see Figure 3b). In particular, it is noteworthy that the strain distribution showed no sensitivity to the hardening parameters used for the simulation (as illustrated in Figure 3c). This outcome is different from the other resulting properties, such 
as the drawing forces or the residual stresses [19]. This observation will be further exploited in Section 3 to develop the parameter identification procedure.

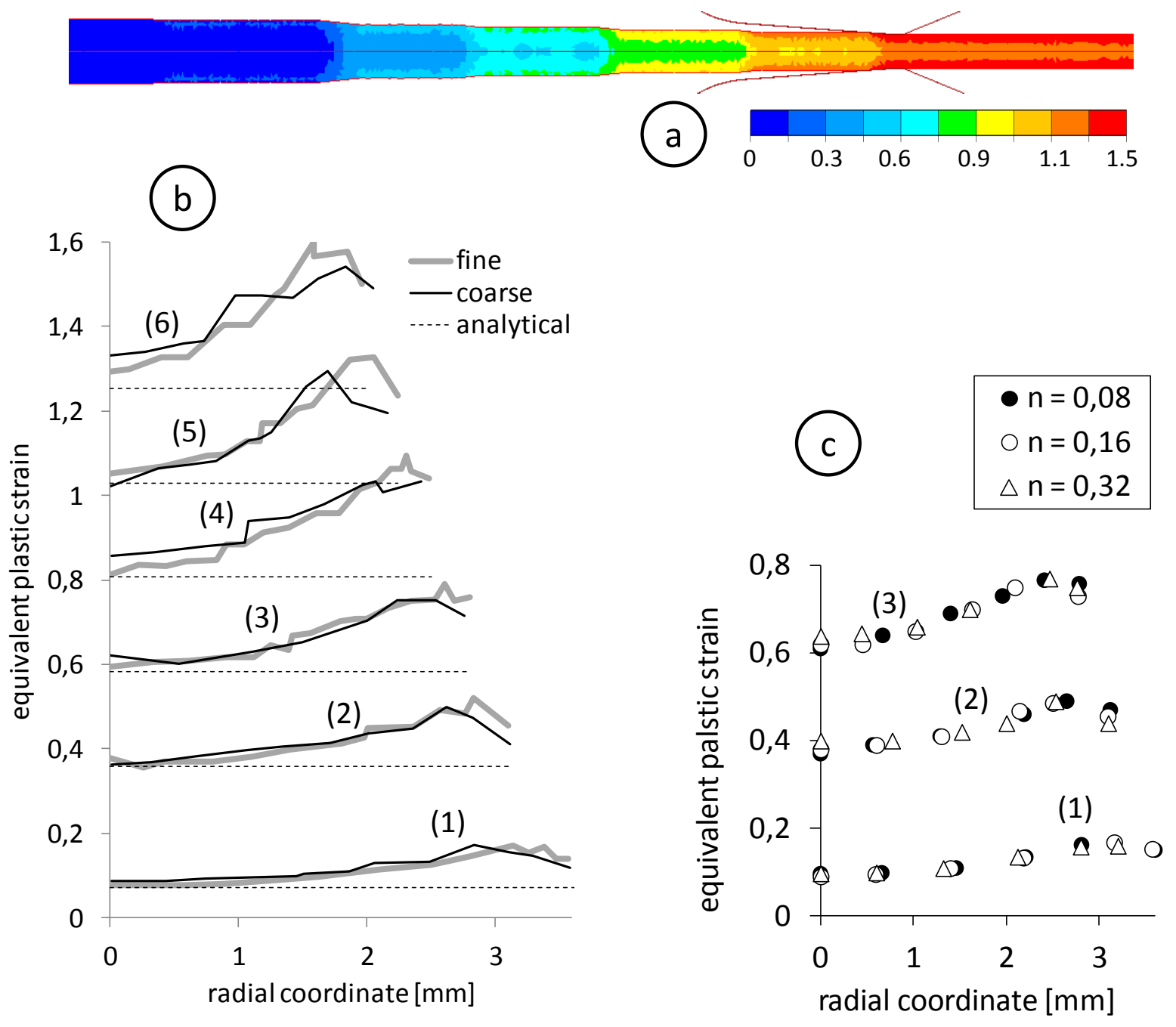

Figure 3. Strain distribution in the cross-section of the drawn wires as calculated by FEA using a Swift hardening law: (a). influence of the mesh size (b) and influence of the hardening coefficient (c).

The FEA simulation of the subsequent tensile tests showed that the strain distribution remains strictly identical to the initial one, uniformly increasing with the amount of tensile strain, as illustrated in Figure 4. As a consequence, a full FEA model is not required for the simulation of these heterogeneous tensile tests. The simulation could be performed analytically, starting from the initial strain distribution calculated from the FEA. This approach drastically decreases the time needed to perform the parameter identification, which requires many computations. 

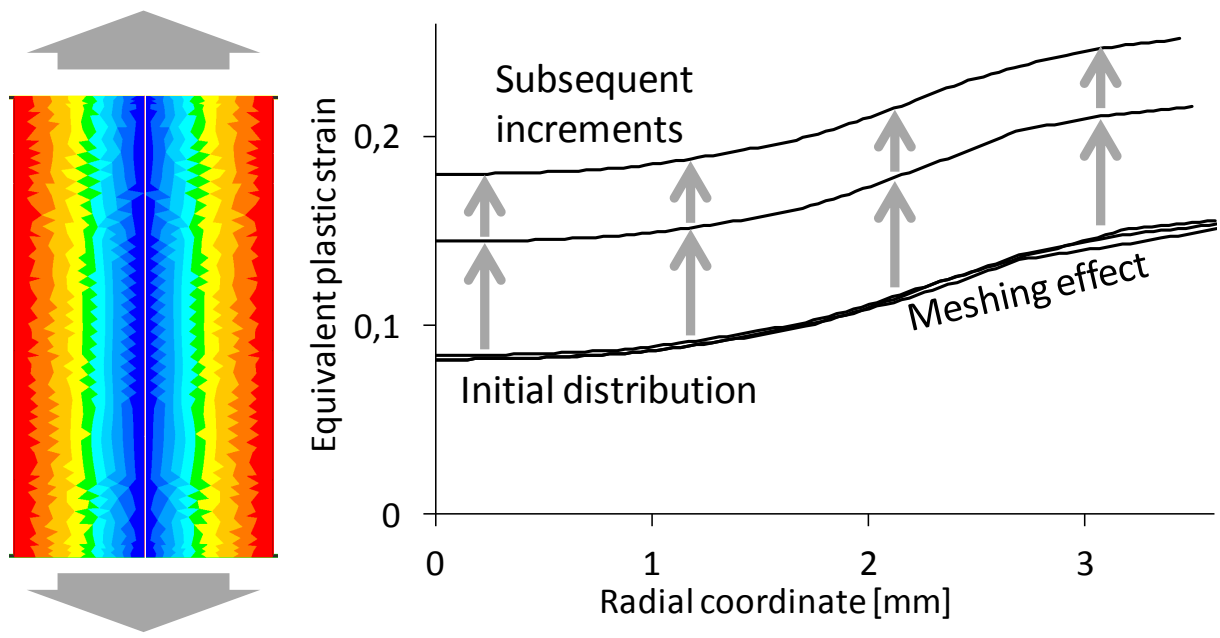

Figure 4. Strain evolution during a tensile test FE simulation following a wire drawing simulation.

The tensile test simulations aim to compute the force $F(t)$ and the displacement $D(t)$ applied on the sample, at each time increment, in order to compare them to the experimentally measured quantities. By integrating the tensile true stress component over the wire's crosssection, the force applied on the sample is calculated as

$$
F(t)=\int_{r=0}^{R(t)} 2 \pi r \sigma_{y}(r, t) d r
$$

since the tensile stress component is equal to the flow stress $\sigma_{y}$ under uniaxial loading. The local yield stress at each material point $r$ and at each time step $t$ is calculated as a function of the equivalent plastic strain

$$
\sigma_{y}(r, t)=f\left(\varepsilon_{e q}(r, t)\right)
$$

Explicit examples of such hardening functions will be given in Section 3. The total equivalent strain is obtained by adding the equivalent strain due to the tensile test $\varepsilon_{e q}^{(U T)}(t)$ to the local pre-strain induced by the drawing passes $\varepsilon_{e q}^{(p r e)}(r)$ prior to the test:

$$
\varepsilon_{e q}(r, t)=\varepsilon_{e q}^{(p r e)}(r)+\varepsilon_{e q}^{(U T)}(t) .
$$

It is noteworthy that in pure uniaxial tension the equivalent strain is identical to the tensile plastic strain component:

$$
\varepsilon_{e q}^{(U T)}(t) \equiv \varepsilon_{11}^{p(U T)}(t)=\varepsilon_{11}^{t o t(U T)}(t)-\varepsilon_{11}^{e l(U T)}(t) .
$$

In a tensile test, one can relate the total tensile strain component $\varepsilon_{11}^{\text {tot(UT) }}(t)$ to the instantaneous change in the sample's length $D(t)$ 


$$
\varepsilon_{11}^{t o t(U T)}(t)=\ln \left(\frac{L(t)}{L_{0}}\right)=\ln \left(1+\frac{D(t)}{L_{0}}\right),
$$

where $L_{0}$ is the initial length of the tensile specimen, $L(t)$ its actual length at time $t$ and $\varepsilon_{11}^{e l(U T)}=\sigma_{11} / E$ with $E$ the Young modulus. An average elastic strain was computed for the entire cross-section at each increment, since complete unloading cannot occur locally. This is the reason for the significant residual stress fields after multiple wire drawing, with tensile residual stresses on the outer surface and compressive stresses at core [20].

This completes the model of uniaxial tension, relating $F(t)$ to $D(t)$. In equation (1), the time evolution of radius $R$ is calculated from the total strain, using volume conservation:

$$
\varepsilon_{11}^{\text {tot }(U T)}(t)=\ln \left(\frac{A_{0}}{A(t)}\right) \text { with } A(t)=2 \pi R(t) .
$$

To summarize, drawing experiments were used to generate large pre-strains in subsequently drawn wires. Tensile tests were used to generate force-displacement tensile curves at six prestrain levels in addition to the initial wire. Given the significant strain heterogeneity in the wires' cross-sections, the experimental curves were not converted into stress-strain curves. Finally, FE simulations were used to reveal the strain distributions in the six wires' transverse cross-sections. These data were used to determine the hardening parameter identification procedure described in Section 3.

\section{Parameter identification procedure}

In a cold forging simulation, $J_{2}$ elasto-plasticity is classically adopted, along with an isotropic hardening model [5], [21], [22]. Rate and temperature effects may also be introduced for some applications, although these were not considered in this investigation. In turn, several hardening models from the literature were adopted, and their parameters identified with respect to the experimental dataset. The equations for the six models considered in the investigation are shown in Eq. (7):

$$
\begin{gathered}
\sigma_{V}=\sigma_{0}+Q(1-\exp (-b \bar{\varepsilon})), \\
\sigma_{S}=k\left(\varepsilon_{0}+\bar{\varepsilon}\right)^{n}, \\
\sigma_{H S h}=A-(A-B) \exp \left[-f\left(\varepsilon_{0}+\bar{\varepsilon}\right)^{g}\right], \\
\sigma_{H S p}=C \tilde{\varepsilon}^{q} \exp \left(p \tilde{\varepsilon}+\frac{m}{\tilde{\varepsilon}}\right) \text { with } \tilde{\varepsilon}=\varepsilon_{0}+\bar{\varepsilon}, \\
\sigma_{S V}=\sigma_{S}+\sigma_{V}, \\
\sigma_{S H S}=\alpha \sigma_{S}+(1-\alpha) \sigma_{H S h},
\end{gathered}
$$

where $\bar{\varepsilon}$ represents the equivalent strain, $\sigma_{V}, \sigma_{S} \ldots$ designate the flow stress and the other terms are constant material parameters. The indices designate the Voce $(V)$, Swift $(S)$, Hockett-Sherby $(H S h)$, and Hansel-Spittel (HSp) models [23], [24] as well as their combinations: Swift-Voce (SV) and Swift-Hockett-Sherby (SHS) [25]. These phenomenological models make use of power and exponential functions in different combinations, involving different numbers of parameters: three $\left(\sigma_{V}, \sigma_{S}\right)$, five $\left(\sigma_{H S h}, \sigma_{H S p}\right)$, six 
$\left(\sigma_{S V}\right)$ or seven $\left(\sigma_{S H S}\right)$. The power law is the simplest and oldest hardening model meant to describe the effect of dislocation density increase [26]. At large strains, as the physical hardening mechanism shifts from planar slip to cross slip, an exponential hardening term can be added to it [27]. At higher strains, flow stress saturation is observed due to restauration and dislocation annihilation, which is approached by Voce's saturating model [28]. The HockettSherby model almost saturates with the combination of the exponential and the power law terms [29]. Finally, the Hansel-Spittel equation is not a rheological model itself, but a combination of sub-models that can be activated / deactivated. Actually, in the rest of the article, one term will be neglected by setting $p=0$, so that $\sigma_{H S p}$ will be computed as

$$
\sigma_{H S p}=C \tilde{\varepsilon}^{q} \exp \left(\frac{m}{\tilde{\varepsilon}}\right) .
$$

This choice is consistent with the material model database used in the Forge NxT software for cold forming, where parameter $p$ is always set to zero to deactivate the corresponding term.

All the physical phenomena occurring during forming were modelled here only with the use of plastic strain. This is of course a simplification or the physical reality, yet such phenomenological models are the basis of nowadays FE process simulation. The physical mechanisms accompanying the hardening phenomenon are not in the focus of the study, but only their macroscopic effect.

The parameters of the different hardening laws were identified to minimize the following cost-function:

$$
\begin{gathered}
\Phi=\sum_{i=1}^{N_{\text {tests }}} \alpha_{i} \Phi_{i} ; \Phi_{i}=\sqrt{\sum_{j=1}^{n_{i}}\left(F_{i, j}^{\text {exp }}-F_{i, j}^{\text {calc }}\right)^{2} /\left\|F_{i}^{\text {exp }}\right\|^{2}} \\
\text { with }\left\|F_{i}^{\text {exp }}\right\|^{2}=\sum_{j=1}^{n_{i}}\left(F_{i, j}^{\text {exp }}\right)^{2},
\end{gathered}
$$

where $N_{\text {tests }}$ designates the number of tensile tests used for the identification (maximum seven, in this case), $n_{i}$ is the number of points on the experimental tensile curve $i$, while $F_{i, j}^{e x p}$ and $F_{i, j}^{c a l c}$ designate the experimental and calculated tensile forces, respectively. The weighting coefficients $\alpha_{i}$ verify the classical condition $\sum_{i} \alpha_{i}=1$.

Although this study aims to show the benefits of using large strain experiments in parameter identification, these benefits should not be obtained at the expense of a poorer accuracy at small strains. To prevent such an artefact, the weight of the first tensile test performed on the undeformed material was set at a value 50 times larger than the rest of the weighting coefficients, which were taken to be equal to each other $\left(\alpha_{i}=\frac{1}{50} \alpha_{0}\right.$, i.e. $\left.\alpha_{0}=50 \alpha_{i}\right)$.

As a first step, the parameters for the six hardening models were identified with respect to the seven available tensile tests (one on the initial wire, and one after each of the six drawing steps). The minimization was performed using both an evolutionary algorithm and a gradienttype algorithm. The evolutionary algorithm was launched several times using several initial guesses to ensure that most of the solution space had been evaluated. After the end of each computation, the gradient algorithm was launched to find the closest best minimum. Then, the evolutionary algorithm was re-launched to widen the possible range of solutions. This 
succession of evolutionary and gradient algorithms was continued until no more improvement was achieved. The parameter space was defined based on the literature. For each model, the maximum and the minimum values for each parameter was set to be in the same order of magnitude as the lowest and biggest already identified parameter found in the literature for any given metallic material. This sequence of identification iterations with different algorithms, including an evolutionary one, is aimed to avoid local minima, although it is impossible to demonstrate that the reached solution is the global optimum.

Figure 5 summarizes the optimum values of the cost function reached for each model and compares the seven predicted and experimental force-displacement curve pairs for each model. 

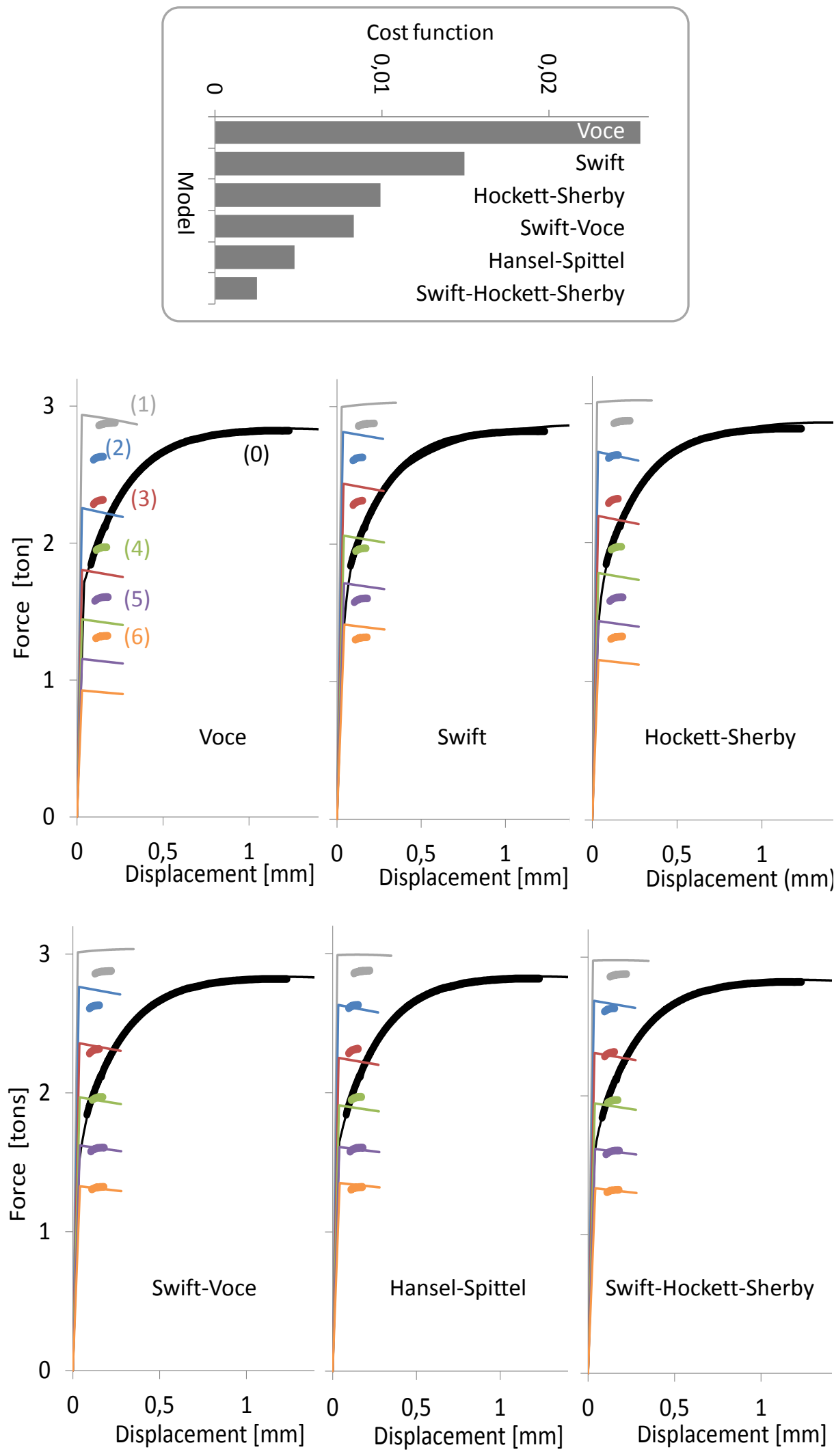

Figure 5. Obtained cost function values (top) and the comparison between the simulated (thin) and experimental (thick) tensile curves corresponding to the identified parameters. The numbers $(i)$ indicate the index of each experimental tensile curve, as defined in Figure 2. 
The simpler Voce and Swift models showed the lowest accuracy. The Hockett-Sherby and Swift-Voce models provided a better prediction. The lowest values of the cost function were obtained with the Swift-Hockett-Sherby model, followed closely by the Hansel-Spittel model. As the cost function decreased below 0.01 , the models fit remarkably well to the seven tensile curves simultaneously.

It is noteworthy that the number of drawing / tensile steps and the amounts of drawing prestrain were chosen relatively arbitrarily. The choice was driven by the drawing process technology and industrial availability rather than by the specific needs of the parameter identification procedure. Consequently, the sensitivity of the parameter identification results to the arbitrary selection of the experimental reference data was investigated by repeating the identification for various sub-sets of the available experimental data. The following combinations of experimental tensile data were considered:

- All available data (designated "0123456"),

- Only the tensile test on the initial wire (designated " 0 "),

- Tensile tests on original wire and after $6^{\text {th }}$ drawing (" 06 "),

- Tensile tests on original wire and after $3^{\text {rd }}$ drawing ("03"),

- Tensile tests on original wire and after $1^{\text {st }}, 2^{\text {nd }}$ and $3^{\text {rd }}$ drawing (“0 0123 ”).

In each of these cases, the parameter identification procedure described above was applied for all the models. The flow curves predicted by the various models with the parameters obtained from the different identifications are summarized in Figure 5. For completeness, the sets of parameter values corresponding to the various identifications are provided in the appendix.

For several models, the predictions obtained using all the available tensile tests (thick blue curves) were significantly different from those obtained when using only the initial curve (thick red curves). This general trend clearly emphasizes the need to include large strain experiments in the parameter identification data. Very often, the addition of only one tensile curve, corresponding to the last drawing pass, significantly improved the prediction. Nonetheless, it is clear from Figure 6 that different input data lead to different flow curves. Moreover, the robustness of the identified parameters with respect to the experimental input is not necessarily increasing with model accuracy. The less robust model with respect to the experimental input data were Hansel-Spittel and Hockett-Sherby, for which the difference of predicted flow stress at a strain of 1 can reach $300 \mathrm{MPa}$ depending of the choice of experimental input. The accurate SHS model exhibited deviations at large strains in one case, when greater accuracy was sought at low and moderate strains (case "0123"). The most robust model appeared to be Swift-Voce. 

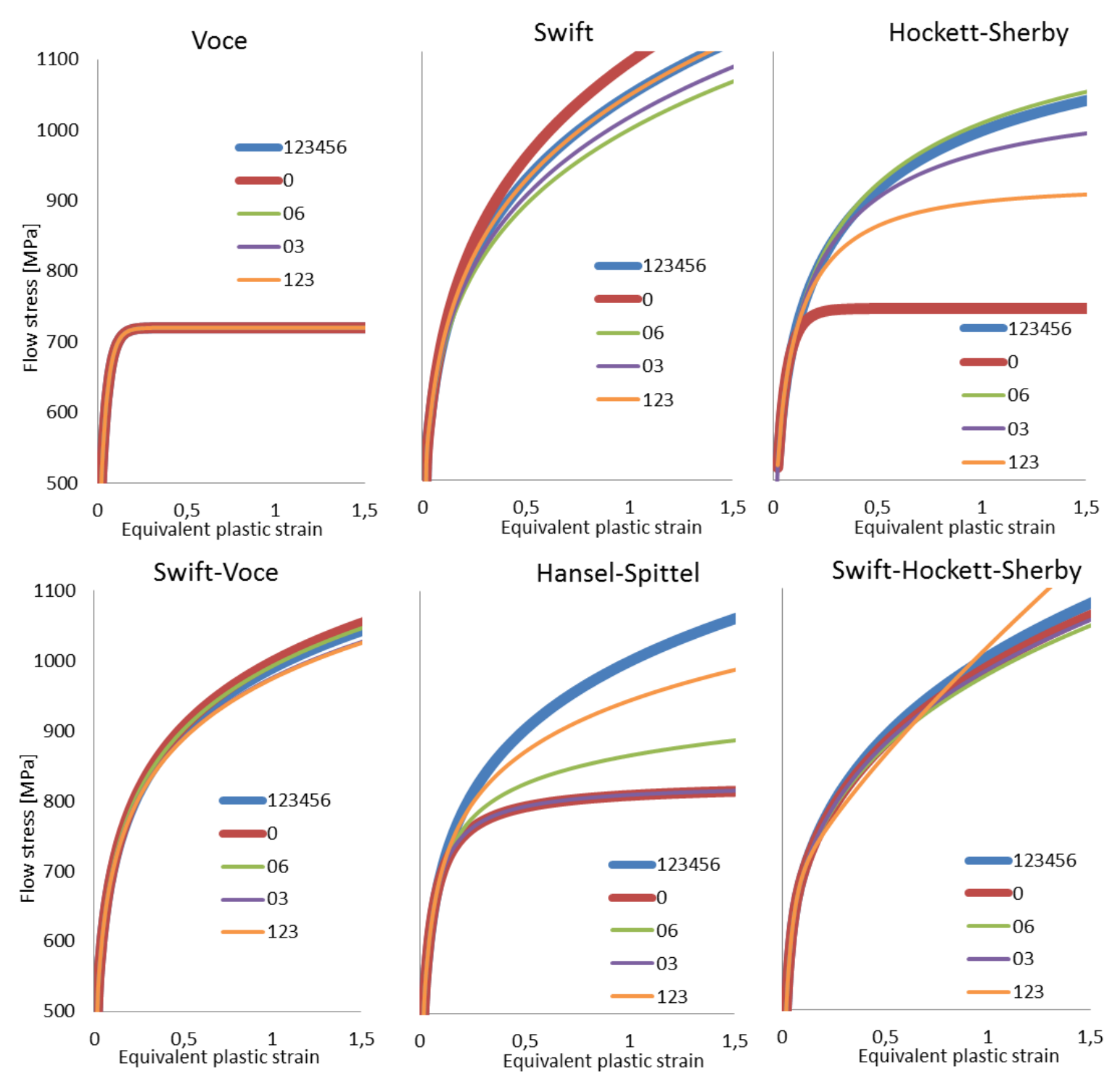

Figure 6. Flow curves of the studied material, as predicted by the various models. The legend indicates the tensile experiments used for the parameter identification for each curve: " 0 " designates the test on the initial wire, and " $i$ " designates the tensile test after the " $i$-th" drawing pass.

These trends were also confirmed by all the models at larger strains - as shown in Figure 7. The SV model appears almost insensitive to the selection of experimental data, up to very large strains. This robustness has already been emphasized in the literature for steels and in particular for sheet metal forming applications [30], [31]. It is noteworthy that the true strain levels of $4 \ldots 5$ that are shown in Figure 7 are much larger than those obtained in the experiments. However, such strains are common in bulk metal forming, making it important to assess the accuracy and robustness of the model predictions for these conditions. 

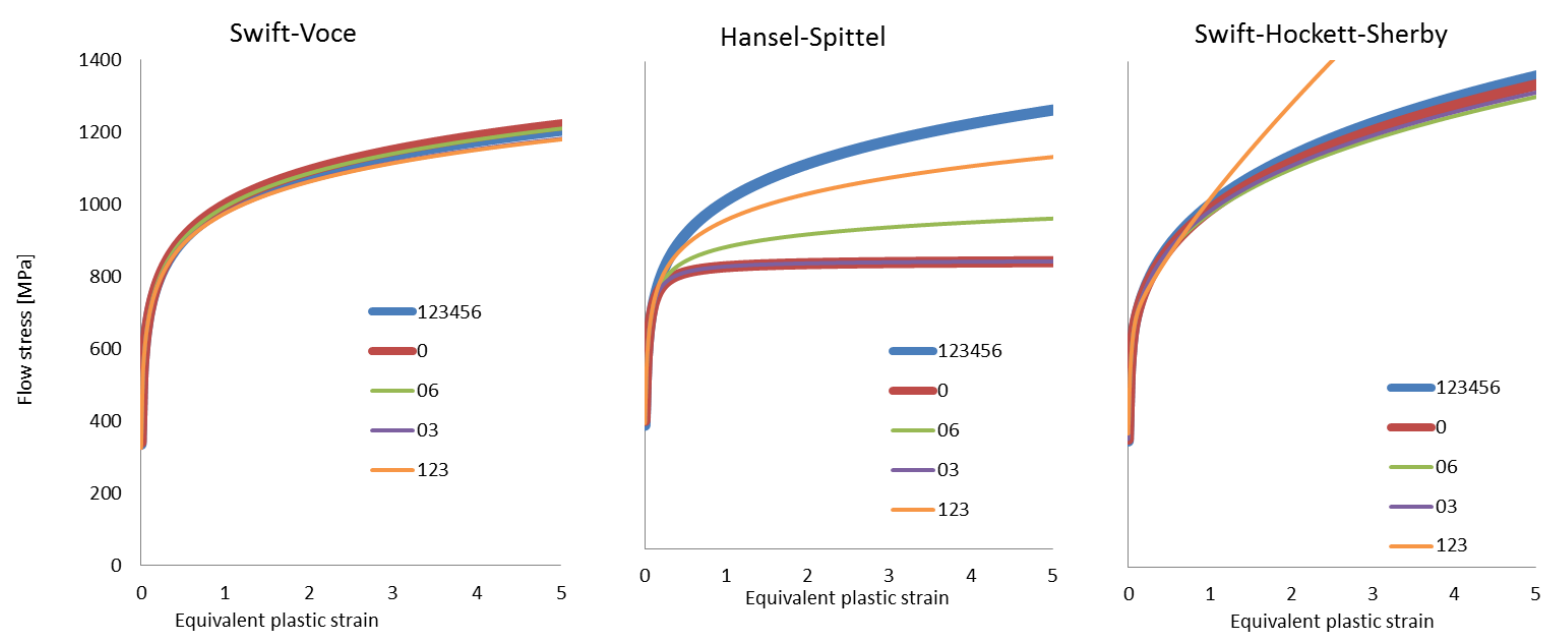

Figure 7. Predicted flow curves for very large strains from the three most accurate models of the series, as identified using various combinations of experimental input data.

\section{Discussion}

The current results corroborate numerous references, confirming that the material flow curves depend significantly on the particular experimental dataset and hardening model used for the parameter identification procedure. Consequently, both the data and the modelling used for this purpose require careful preparation.

The wire drawing process gives rise to large strains and delays necking due to the locally low stress triaxiality values. One drawback associated with this pre-straining approach is the heterogeneous characteristic of the resulting strain distribution. In previous investigations, promising results were obtained by replacing the real strain distribution with the uniform ideal pre-strain value calculated from the wire diameter reduction [11], [18]. With this simplified procedure, experimental stress-strain curves can be extracted from tensile tests. These experimental curves, shifted right by the corresponding pre-strain, would describe successive segments of the material's flow curve. To explore the accuracy of this hypothesis, the drawing ratio of the first drawing step in our series was set to a value significantly smaller than the material's uniform elongation. In this way, the experimental flow curve segment corresponding to this first drawn wire should overlay the experimental flow curve of the original wire. Figure 8a shows the experimental true stress-strain curves corresponding to the original wire and to the first drawn wire offset by the corresponding ideal pre-strain. The two curves do not overlap due to the ideal value of the drawing strain being smaller than the real strains induced by the real process. It is noteworthy that this error accumulates as the number of drawing sequences increases. Consequently, the resulting flow curve will lay higher, compared to the procedure using the FE-predicted pre-strains, as illustrated in Figure 8b.

The gap in this figure shows that the benefits decrease when using the large strain experiments. The observed inconsistency may depend on the model, experiments and weighting factors used during the identification. Figure 9 shows the flow curves obtained with 
the FEA and analytical pre-strains, respectively, using the SHS model, the complete set of seven tensile tests and equal weighting factors $\left(\alpha_{0}=\alpha_{1}=\cdots \alpha_{7}\right)^{2}$. The value of the cost function was 0.0027 (FEA) and 0.0024 (analytical). However, the errors in the analytical strain distributions were compensated by the high flexibility of the model resulted in spurious inflexions in the flow curve, which significantly reduced the usefulness of the large strain dataset. Similar conclusions have been drawn in the literature concerning parameter identification for anisotropic yield functions with increasing flexibility [32].
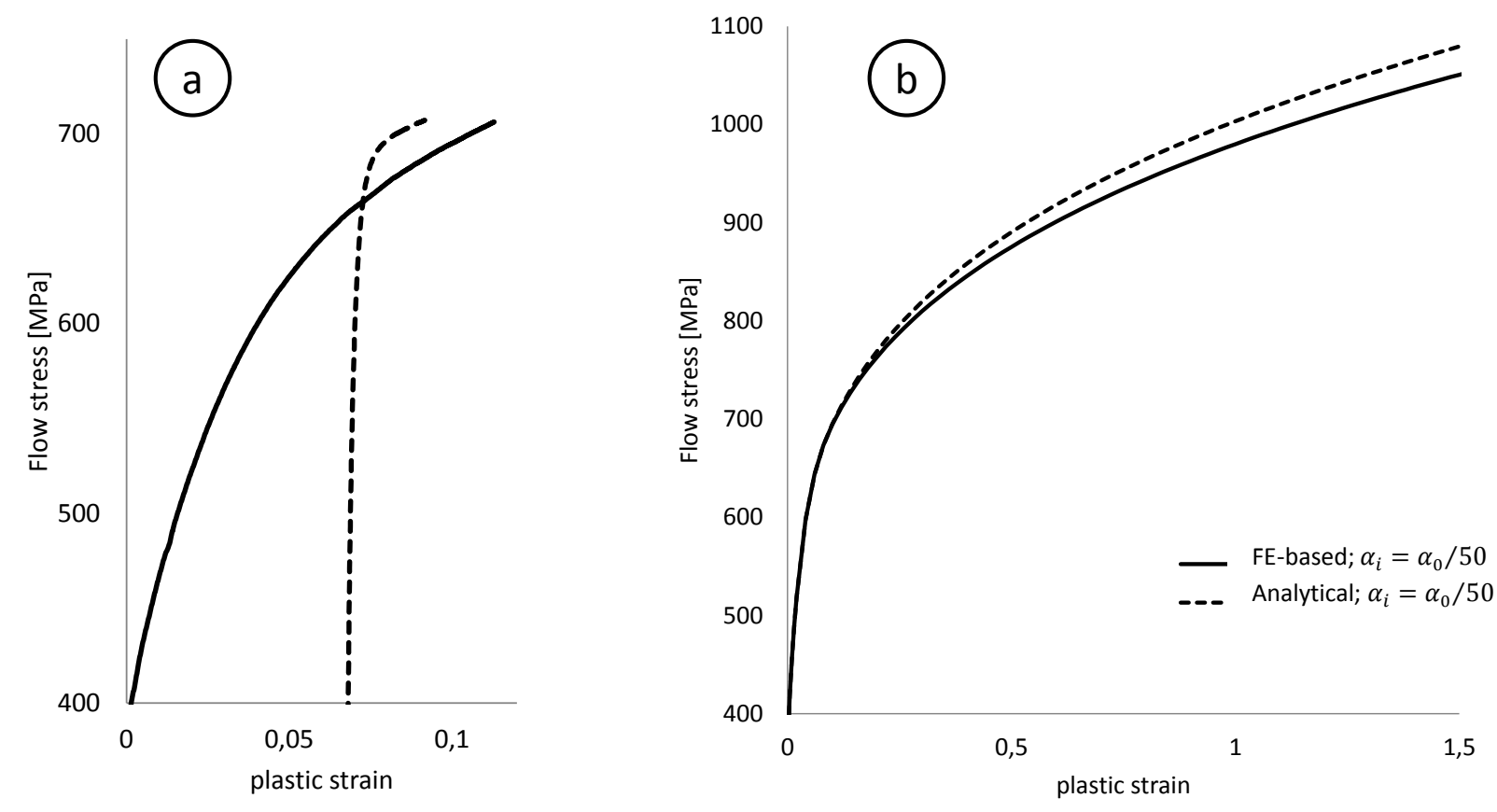

Figure 8. a) Experimental flow curves corresponding to the original wire (solid line) and to the first drawn wire (dashed). The latter curve is offset by the ideal strain corresponding to the diameter reduction from 7.5 to $7.24 \mathrm{~mm}$ during the first drawing sequence. b) Flow curves calculated using the SHS model, the seven tensile curves and the pre-strains determined by FE (solid line) or analytically (dashed line).

\footnotetext{
${ }^{2}$ As a reminder, until now, all the optimisations have been made with the tensile curve corresponding to the undrawn wire weighted 50 times more than the others in the cost function.
} 


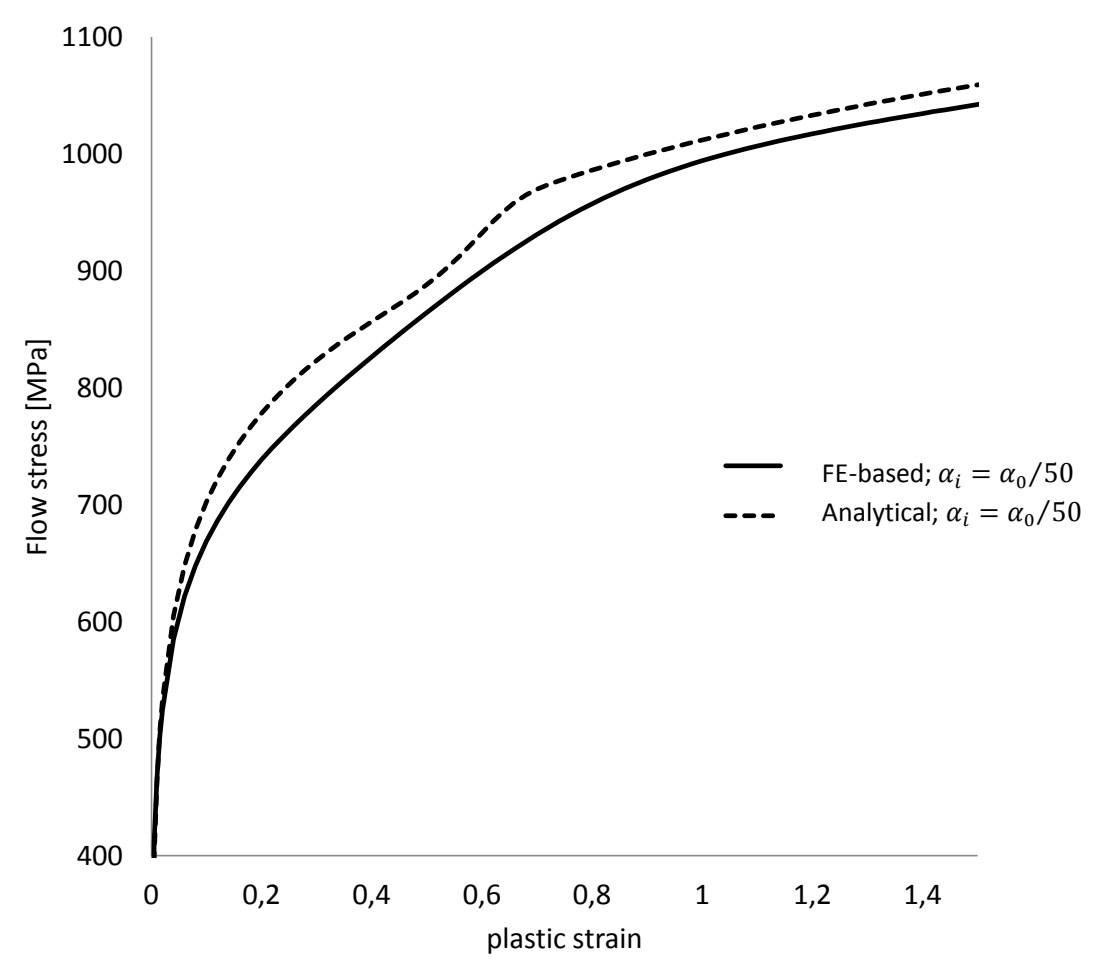

Figure 9. Flow curves calculated using the SHS model: the seven tensile curves and prestrains are determined by FE (solid line) or analytically (dashed line). The weights of all the seven tensile curves (including the original one) were set to be equal to each other.

These observations further underline the importance of taking the heterogeneous strain distribution into account, as proposed in this paper. Nevertheless, strain ranges in excess of that covered by these experiments show that the flow curve predictions are still subject to potential errors, as illustrated by the comparison of the various models in the previous section. From the various trials, the Swift-Voce model, although not the most accurate model, combines very good accuracy with excellent robustness at large strains, as already underlined in the literature [30], [31]. As a consequence, the following procedure could be adopted to enhance the robustness of the identified parameters:

- Identify the Swift-Voce model using the available experiments. In addition to the stress values, the slope at the end of the last tensile curve can be added to the cost function for optimal robustness.

- Calculate the stress value predicted by the Swift-Voce model for a large strain - typically, the largest strain level envisioned in the foreseen applications.

- Add this "virtual" point to the experimental data set - possibly with a relatively lower weight, depending on the degree of confidence in the Swift-Voce model for the particular material being studied.

- Identify the favourite - or imposed - model with respect to this enhanced data set.

This procedure provides the best fit to the available experiments, with an additional attempt for protection against large strain deviations. The idea was applied to the current case using the Hansel-Spittel and the Swift-Hockett-Sherby models. A "virtual point" was calculated 
with the Swift-Voce model for an arbitrary strain equal to 5. The resulting flow curves are shown in Figure 10, along with the flow curves determined without the virtual point (in both cases, the entire set of available tensile curves were used). The use of the virtual point had an influence on the results, as the strain values reach significantly outside the range covered by the experiments. The differences were more significant for the Hansel-Spittel model, especially as all its terms were activated for the sake of illustration. In the case of the more robust SHS law, the influence of the virtual point was weaker. Its effect could be controlled by increasing the weight of the virtual point in the cost function. These preliminary results illustrate the potential of this approach. However, further investigations are required to conclude about its real usefulness and to establish a general solution for the choice of the virtual point, its weight etc.
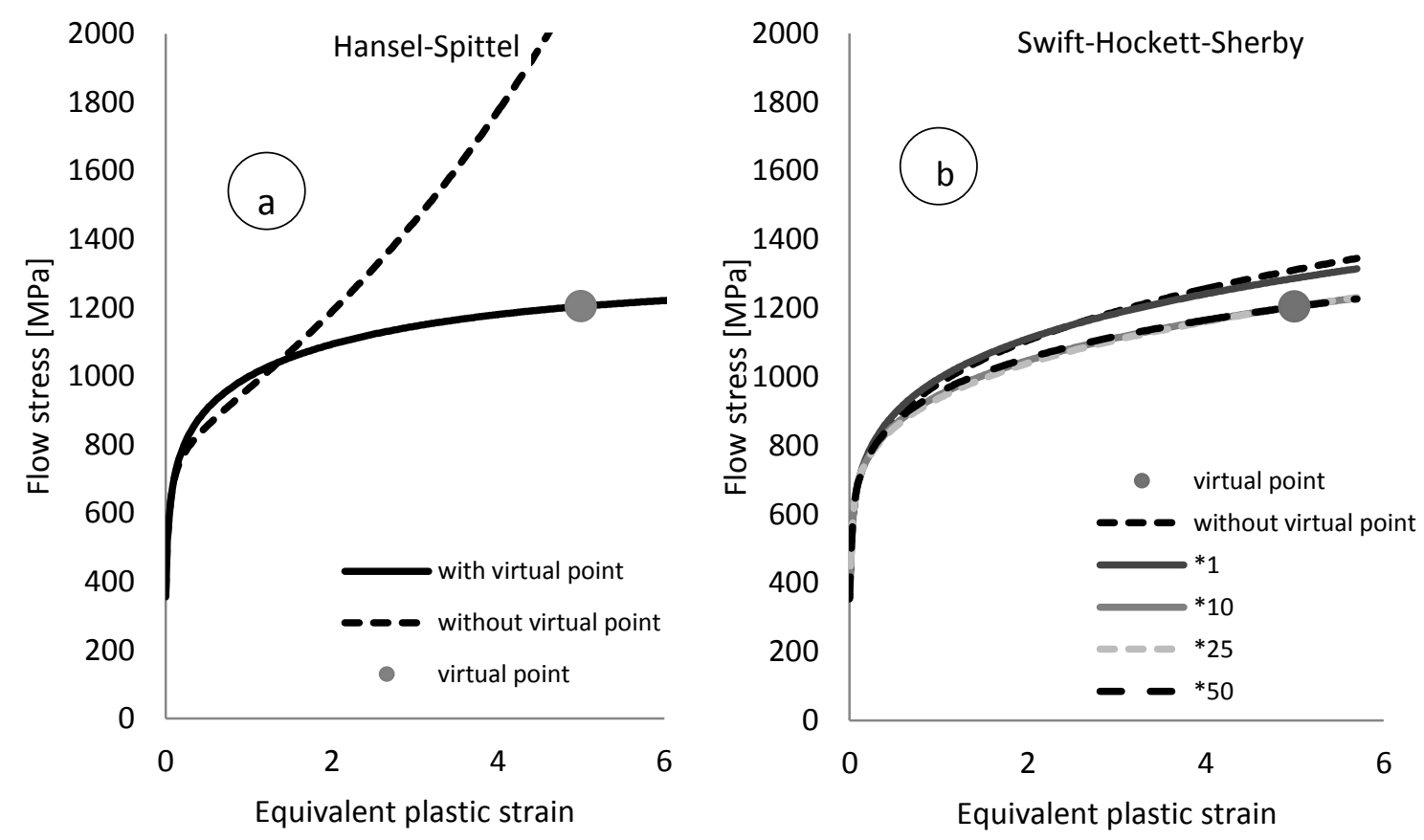

Figure 10. a) Flow curves calculated using the HSp model by adding a virtual point to the optimization process (solid line) to the seven tensile curves or without it (dashed line). The point has the same weight as a tensile curve in the identification process. b) Flow curves calculated with SHS model by adding a virtual point to the optimization process to the seven tensile curves or without it. Different curves correspond to different weights of the point in the identification process. 


\section{Summary and conclusions}

The main objective of this work was to simplify the experimental procedure required for accurate large strain parameter identification of the hardening laws in cold bulk metal forming. For this purpose, industrial wire drawing experiments were successfully used. Large strain levels were achieved using this method, which increased the range of applicability of the identified parameters. The material response was quantified using classic tensile tests. These indirectly reflected the process effect without requiring any measurements during the forming process itself. The strain field due to drawing was strongly heterogeneous, but the tensile test could be analysed analytically. Consequently, the parameter identification procedure was decoupled from the FE simulation for efficiency. As a potential extension, the same approach could be extended to rolling, for the large strain hardening characterizations of either bulk or sheet metals.

The relative accuracy and robustness of several hardening models were investigated over a strain range up to 1.5. The best accuracy was obtained using the Swift-Hockett-Sherby model, followed closely by the Hansel-Spittel and Swift-Voce models. In terms of robustness, the Swift-Voce model showed the lowest sensitivity to the available input data. Consequently, this model could serve to enhance the identification robustness at large strains for any other preferred (or imposed) model. The Swift-Hockett-Sherby model was the most accurate and, with one exception, exhibited low sensitivity to the experimental inputs.

\section{Acknowledgements}

The authors are grateful to Mario Confente and Marie-Thèrese Perrot-Simonetta from ArcelorMittal Gandrange (formerly CRIE, ISPAT Unimetal), France, for supporting the initial stages of the study and for providing the experimental data.

Conflict of Interest: The material and experimental data was provided by ArcelorMittal Gandrange (formerly CRIE, ISPAT Unimetal), France. The authors received a grant from this company in 2004 for an early study using this data. The authors have no other conflict of interest.

\section{References}

[1] M. Avrami, "Kinetics of Phase Change. I General Theory," J. Chem. Phys., vol. 7, no. 12, pp. 1103-1112, 1939.

[2] P. F. Bariani, T. Dal Negro, and S. Bruschi, "Testing and modelling of material response to deformation in bulk metal forming," CIRP Ann.-Manuf. Technol., vol. 53, no. 2, pp. 573-595, 2004. 
[3] Y. C. Lin and X.-M. Chen, "A critical review of experimental results and constitutive descriptions for metals and alloys in hot working," Mater. Des., vol. 32, no. 4, pp. 17331759, Apr. 2011.

[4] J. C. Gelin and O. Ghouati, "The inverse approach for the determination of constitutive equations in metal forming," CIRP Ann.-Manuf. Technol., vol. 44, no. 1, pp. 189-192, 1995.

[5] A. Gavrus, E. Massoni, and J. L. Chenot, "An inverse analysis using a finite element model for identification of rheological parameters," J. Mater. Process. Technol., vol. 60, no. 1, pp. 447-454, 1996.

[6] M. Pietrzyk and J. Jedrzejewski, "Identification of parameters in the history dependent constitutive model for steels," CIRP Ann.-Manuf. Technol., vol. 50, no. 1, pp. 161-164, 2001.

[7] S. Bruschi et al., "Testing and modelling of material behaviour and formability in sheet metal forming," CIRP Ann., vol. 63, no. 2, pp. 727-749, 2014.

[8] A. Gavrus, E. Massoni, and J.-L. Chenot, "Thermo-viscoplastic parameter identification formulated as an inverse finite element analysis of the hot torsion test," Steel Res. Int., vol. 70, no. 7, pp. 259-268, 1999.

[9] D. Szeliga and M. Pietrzyk, "Testing of the inverse software for identification of rheological models of materials subjected to plastic deformation," Arch. Civ. Mech. Eng., vol. 7, no. 1, pp. 35-52, 2007.

[10] T.-S. Cao, C. Vachey, P. Montmitonnet, and P.-O. Bouchard, "Comparison of reduction ability between multi-stage cold drawing and rolling of stainless steel wire Experimental and numerical investigations of damage," J. Mater. Process. Technol., vol. 217, pp. 30-47, Mar. 2015.

[11] D. J. Celentano, M. A. Palacios, E. L. Rojas, M. A. Cruchaga, A. A. Artigas, and A. E. Monsalve, "Simulation and experimental validation of multiple-step wire drawing processes," Finite Elem. Anal. Des., vol. 45, no. 3, pp. 163-180, Feb. 2009.

[12] C. M. Young, L. J. Anderson, and O. D. Sherby, "On the steady state flow stress of iron at low temperature and large strains," Metall. Trans., vol. 5, no. 2, pp. 519-520, Feb. 1974.

[13] U. S. Dixit and P. M. Dixit, "An analysis of the steady-state wire drawing of strainhardening materials," J. Mater. Process. Technol., vol. 47, no. 3-4, pp. 201-229, Jan. 1995.

[14] J. Luksza, J. Majta, M. Burdek, and M. Ruminski, "Modelling and measurements of mechanical behaviour in multi-pass drawing process," J. Mater. Process. Technol., vol. 80-81, pp. 398-405, Aug. 1998.

[15] A. Skolyszewski, J. Łuksza, and M. Paćko, "Some problems of multi-stage fine wire drawing of high-alloy steels and special alloys," J. Mater. Process. Technol., vol. 60, no. 1-4, pp. 155-160, Jun. 1996.

[16] T. Kuboki, M. Abe, Y. Neishi, and M. Akiyama, "Design Method of Die Geometry and Pass Schedule by Void Index in Multi-Pass Drawing," J. Manuf. Sci. Eng., vol. 127, no. 1, p. 173, 2005. 
[17] T. Balan, R. Bigot, M. T. Perrot-Simonetta, and M. Confente, "Plasticity parameters identification for steel wires," presented at the Int. Conf. ESAFORM 2005, Cluj-Napoca, 2005, pp. 53-56.

[18] T. Massé, Y. Chastel, P. Montmitonnet, C. Bobadilla, N. Persem, and S. Foissey, "Impact of mechanical anisotropy on the geometry of flat-rolled fully pearlitic steel wires," J. Mater. Process. Technol., vol. 211, no. 1, pp. 103-112, Jan. 2011.

[19] A. Panteghini and F. Genna, "Effects of the strain-hardening law in the numerical simulation of wire drawing processes," Comput. Mater. Sci., vol. 49, no. 2, pp. 236-242, Aug. 2010.

[20] J. M. Atienza and M. Elices, "Influence of residual stresses in the tensile test of cold drawn wires," p. 5.

[21] J. C. Simo, "Numerical analysis and simulation of plasticity," in Handbook of Numerical Analysis, vol. 6, Elsevier, 1998, pp. 183-499.

[22] A. Halouani, Y. Li, B. Abbès, and Y.-Q. Guo, "Simulation of axi-symmetrical cold forging process by efficient pseudo inverse approach and direct algorithm of plasticity," Finite Elem. Anal. Des., vol. 61, pp. 85-96, Nov. 2012.

[23] A. Hensel and T. Spittel, Kraft und Arbeitsbedarf bildsamer Formgebungsverfahren. Leizig: VEB Deutscher Verlag für Grundstoffindustrie, 1978.

[24] P. Petrov and M. Abbod, "Analysis of rheological behavior of AL-CU-MG-FE-NI alloy at elevated temperatures using phenomenological flow stress model," Int. J. Mater. Form., vol. 2, no. S1, pp. 371-374, Aug. 2009.

[25] D. Banabic and M. Sester, "Influence of Material Models on the Accuracy of the Sheet Forming Simulation,” Mater. Manuf. Process., vol. 27, no. 3, pp. 273-277, Mar. 2012.

[26] H. W. Swift, "Plastic instability under plane stress," J. Mech. Phys. Solids, vol. 1, pp. 1$18,1952$.

[27] D. C. Ludwigson, "Modified stress-strain relation for FCC metals and alloys," Metall. Trans., vol. 2, no. 10, pp. 2825-2828, Oct. 1971.

[28] E. Voce, "The relationship between stress and strain for homogeneous deformations," $J$. Inst. Met., vol. 74, pp. 537-562, 1948.

[29] J. E. Hockett and O. D. Sherby, "Large strain deformation of polycrystalline metals at low homologous temperature," J. Mech. Phys. Solids, vol. 23, pp. 87-98, 1975.

[30] X. Lemoine, "Behavior Laws And Their Influences On Numerical Prediction," presented at the 10th Esaform Conference on Material Forming, Zaragoza, Spain, 2007, vol. 907, pp. 269-274.

[31] J. H. Sung, J. H. Kim, and R. H. Wagoner, "A plastic constitutive equation incorporating strain, strain-rate, and temperature," Int. J. Plast., vol. 26, no. 12, pp. 1746-1771, Dec. 2010 .

[32] M. Rabahallah et al., "PARAMETER IDENTIFICATION OF ADVANCED PLASTIC POTENTIALS AND IMPACT ON PLASTIC ANISOTROPY PREDICTION," Int. $J$. Plast., vol. 25, no. 3, pp. 491-512, 2009. 


\section{Appendix}

The following tables present the numerical values of the parameters associated with the different models used in figure 6 .

\begin{tabular}{|l|c|c|c|}
\hline \multicolumn{3}{|c|}{ Voce } \\
\hline $\mathrm{n}^{\circ}$ of tensile test & \multicolumn{3}{|c|}{ parameters } \\
\hline & $\sigma_{0}$ & $Q$ & $b$ \\
\cline { 2 - 4 } $0,1,2,3,4,5,6$ & 381,652 & 338,290 & 25,402 \\
0 & 381,502 & 338,549 & 25,386 \\
0,6 & 381,699 & 338,214 & 25,406 \\
0,3 & 381,852 & 338,159 & 25,376 \\
$0,1,2,3$ & 381,725 & 338,161 & 25,411 \\
\hline
\end{tabular}

\begin{tabular}{|l|r|r|c|}
\hline \multicolumn{4}{|c|}{ Swift } \\
\hline $\mathrm{n}^{\circ}$ of tensile test & \multicolumn{3}{|c|}{ parameters } \\
\hline & \multicolumn{1}{|c|}{$k$} & $\varepsilon_{0}$ & $n$ \\
\cline { 2 - 4 } $0,1,2,3,4,5,6$ & 1039,455 & 0 & 0,175 \\
0 & 1085,364 & 0,0011 & 0,190 \\
0,6 & 991,226 & 0 & 0,162 \\
0,3 & 1008,458 & 0 & 0,167 \\
$0,1,2,3$ & 1039,154 & 0 & 0,175 \\
\hline
\end{tabular}

\begin{tabular}{|l|r|r|r|r|r|}
\hline \multicolumn{7}{|c|}{ Hockett-Sherby } \\
\hline $\mathrm{n}^{\circ}$ of tensile test & \multicolumn{5}{|c|}{ parameters } \\
\hline & \multicolumn{1}{|c|}{$A$} & \multicolumn{1}{|c|}{$B$} & $\varepsilon_{0}$ & \multicolumn{1}{c|}{$f$} & $g$ \\
\cline { 2 - 6 } $0,1,2,3,4,5,6$ & 1166,977 & 208,017 & 0 & 1,687 & 0,370 \\
0 & 740,931 & 361,632 & 0 & 15,221 & 0,857 \\
0,6 & 1177,076 & 222,540 & 0 & 1,687 & 0,384 \\
0,3 & 1032,270 & 252,082 & 0 & 2,363 & 0,440 \\
$0,1,2,3$ & 908,632 & 275,742 & 0 & 3,542 & 0,505 \\
\hline
\end{tabular}

\begin{tabular}{|c|c|c|c|c|c|}
\hline \multicolumn{6}{|c|}{ Hansel-Spittel } \\
\hline $\mathrm{n}^{\circ}$ of tensile test & \multicolumn{5}{|c|}{ parameters } \\
\hline & $C$ & $q$ & $\varepsilon_{0}$ & $m$ & $p$ \\
\hline $0,1,2,3,4,5,6$ & 1005,632 & 0,141 & 0,014 & $-0,006$ & 0 \\
\hline 0 & 828,738 & 0 & 0,027 & $-0,022$ & 0 \\
\hline 0,6 & 880,521 & 0,048 & 0,023 & $-0,016$ & 0 \\
\hline 0,3 & 829,567 & 0 & 0,027 & $-0,022$ & 0 \\
\hline $0,1,2,3$ & 953,4 & 0,104 & 0,018 & $-0,01$ & 0 \\
\hline
\end{tabular}




\begin{tabular}{|l|c|c|c|c|c|c|}
\hline \multicolumn{7}{|c|}{ Swift-Voce } \\
\hline $\mathrm{n}^{\circ}$ of tensile test & \multicolumn{7}{|c|}{ parameters } \\
\hline & $k$ & $\sigma_{0}$ & $\varepsilon_{0}$ & $Q$ & $b$ & $n$ \\
\cline { 2 - 7 } $0,1,2,3,4,5,6$ & 7323,237 & $-6334,383$ & 0,0055 & 10,881 & 0 & 0,018 \\
0 & 7328,249 & $-6330,433$ & 0,0062 & 10,881 & 0 & 0,018 \\
0,6 & 7339,919 & $-6348,145$ & 0,0057 & 10,881 & 0 & 0,018 \\
0,3 & 7335,467 & $-6360,378$ & 0,0044 & 10,882 & 0 & 0,017 \\
$0,1,2,3$ & 7473,528 & $-6499,552$ & 0,0044 & 10,885 & 0 & 0,017 \\
\hline
\end{tabular}

\begin{tabular}{|l|r|r|r|r|r|r|r|c|}
\hline \multicolumn{10}{|c|}{ Swift-Hockett-Sherby } \\
\hline $\mathrm{n}^{\circ}$ of tensile test & \multicolumn{1}{|c|}{$\varepsilon_{0}$} & \multicolumn{1}{|c|}{$n$} & $A$ & \multicolumn{1}{c|}{$B$} & $f$ & \multicolumn{1}{c|}{$g$} & $\alpha$ \\
\hline & \multicolumn{1}{|c|}{$k$} & \multicolumn{1}{|c|}{ parameters } \\
\cline { 2 - 9 } $0,1,2,3,4,5,6$ & 46664,763 & 0,0013 & 0,263 & 355,637 & 248,025 & 121,567 & 1,383 & 0,013 \\
0 & 47010,589 & 0,0013 & 0,270 & 357,717 & 252,138 & 126,322 & 1,389 & 0,014 \\
0,6 & 45705,948 & 0,0020 & 0,252 & 337,699 & 229,170 & 112,979 & 1,357 & 0,014 \\
0,3 & 45930,647 & 0,0016 & 0,248 & 320,180 & 222,358 & 150,332 & 1,441 & 0,015 \\
$0,1,2,3$ & 9838,693 & 0 & 0,772 & 671,095 & 384,973 & 27,317 & 0,961 & 0,038 \\
\hline
\end{tabular}

The next table corresponds to figure $8 \mathrm{~b}$.

\begin{tabular}{|c|c|c|c|c|c|c|c|c|}
\hline \multicolumn{9}{|c|}{ Swift-Hockett-Sherby $\alpha_{0}=50 \alpha_{i}$} \\
\hline FEM/Analytic & \multicolumn{8}{|c|}{ parameters } \\
\hline & $k$ & $\varepsilon_{0}$ & $n$ & $A$ & $B$ & $f$ & $g$ & $\alpha$ \\
\hline FEM & 46664,763 & 0,0013 & 0,263 & 355,637 & 248,025 & 121,567 & 1,383 & 0,013 \\
\hline Analytic & 53103,363 & 0,0012159 & 0,25864 & 318,241 & 231,302 & 213,735 & 1,536 & 0,013 \\
\hline
\end{tabular}

The next table corresponds to figure 9 .

\begin{tabular}{|c|c|c|c|c|c|c|c|c|}
\hline \multicolumn{9}{|c|}{ Swift-Hockett-Sherby $\alpha_{0}=\alpha_{i}$} \\
\hline FEM/Analytic & \multicolumn{8}{|c|}{ parameters } \\
\hline & $k$ & $\varepsilon_{0}$ & $n$ & $A$ & $B$ & $f$ & $g$ & $\alpha$ \\
\hline FEM & 4551,7194 & 0 & 0,06241 & $-1194,5$ & -1351 & 3,30172 & 2,777 & 0,382 \\
\hline Analytic & 11165,258 & 04284 & 0,02832 & $-4868,4$ & $-4949,5$ & 129,125 & 9,71 & 0,367 \\
\hline
\end{tabular}

The next tables corresponds to figure 10 .

\begin{tabular}{|l|r|c|c|c|c|}
\hline \multicolumn{6}{|c|}{ Hansel-Spittel } \\
\hline with/without virtual point & \multicolumn{5}{|c|}{ parameters } \\
\hline \multirow{3}{*}{ without point } & \multicolumn{1}{|c|}{$C$} & $q$ & $\varepsilon_{0}$ & $m$ & \multicolumn{1}{|c|}{$p$} \\
\cline { 2 - 6 } with point & 803,730 & 0,006 & 0,0251 & $-0,019$ & 0,196 \\
\hline
\end{tabular}


Swift-Hockett-Sherby

\begin{tabular}{|c|c|c|c|c|c|c|c|c|}
\hline with/without virtual point & \multicolumn{8}{|c|}{ parameters } \\
\hline & $k$ & $\varepsilon_{0}$ & $n$ & $A$ & $B$ & $f$ & $g$ & $\alpha$ \\
\hline without point & 46664,763 & 0,0012855 & 0,2629 & 355,637 & 248,025 & 121,567 & 1,383 & 0,013 \\
\hline$* 1$ & 76067,587 & 0,0033702 & 0,16929 & 59,6358 & 0,52047 & 585,551 & 1,82 & 0,012 \\
\hline$* 10$ & 50143,952 & 0,0100075 & 0,19554 & 247,273 & 90,8602 & 46,8484 & 1,084 & 0,014 \\
\hline$* 25$ & 43184,461 & 0,0012886 & 0,24941 & 400,239 & 266,716 & 119,717 & 1,45 & 0,013 \\
\hline$* 50$ & 79075,478 & 0,0029551 & 0,15542 & 78,4894 & 0,51894 & 588,06 & 1,867 & 0,011 \\
\hline
\end{tabular}

